\title{
Denosumab is not associated with risk of malignancy: systematic review and meta-analysis of randomized controlled trials
}

\author{
D. Rosenberg ${ }^{1,2}$ (I) $\cdot$ T. Avni ${ }^{1,3} \cdot$ G. Tsvetov ${ }^{3,4} \cdot$ A. Gafter-Gvili ${ }^{1,4} \cdot$ T. Diker-Cohen ${ }^{1,3,4}$
}

Received: 20 May 2021 / Accepted: 13 June 2021 / Published online: 12 August 2021

(C) International Osteoporosis Foundation and National Osteoporosis Foundation 2021

To the Editor,

We read the letter by Jiasong Zhao and colleagues and thank the opportunity to discuss some comments.

Zhao et al. raised concerns about excluding trials that reported no malignancies in both arms; yet, as clarified in the Methods, we have specifically addressed this issue by two methods, both by calculating the risk difference, which takes into account all studies, even when there are no events in either group [1], and by using the value 1 instead of 0 in the event counter, thus enabling those trials to be used for calculation of the relative risk [2]. All results, regardless of the method used, and including Zhao et al.'s re-analysis using the random-intercept generalized linear mixed models, were consistent. Notably, we used the fixed-effect model throughout all analyses since all trials in the meta-analysis had low heterogeneity $\left(\mathrm{I}^{2}=0 \%\right)$, consistent with the Cochrane book methodology. Also, in both the fixed-effect and randomintercept generalized linear mixed models conducted by Zhao et al., the point estimate of $\mathrm{RR}=1.08$ is identical; the result by Zhao et al. can therefore be viewed as a sensitivity analysis and is consistent with our results.

Next, Zhao et al. comment on the short follow-up time of the trials in the meta-analysis. Although one-third of the studies, which included data on 15,596 patients, had a total duration of drug exposure of 24 months or more (Table 1) [3], we agree that longer term drug exposure is needed for conclusive

D. Rosenberg

roza.dana@gmail.com

1 Medicine A, Rabin Medical Center - Beilinson Hospital, Petah Tikva, Israel

2 Department of Rheumatology, Tel Aviv Sourasky Medical Center, 6 Weizmann St, 6423906 Tel Aviv, Israel

3 Diabetes and Metabolism, Rabin Medical Center - Beilinson Hospital, Institute of Endocrinology, Petah Tikva, Israel

4 Sackler Faculty of Medicine, Tel Aviv University, Tel Aviv, Israel assessment of the risk of malignancy. This is exhaustively discussed in the manuscript of our meta-analysis (see "Discussion" and "Limitations").

Also, Zhao et al. found by their methodology a statistically significant association between duration of drug exposure and a relative risk for malignancy of $1.04(95 \% \mathrm{CI} 1.02,1.06)$ and point out that the $R R=1.08$ would translate into an increase of $8 \%$ in risk of malignancy. Such a point estimate is hard to interpret and is debated for its clinical significance. We conclude that considering the currently available prospective data there is no evidence for increased risk of malignancy with exposure to denosumab of up to 48 months; still, we fully agree that prolonged post-marketing surveillance is required to detect potential long-term effects of drug exposure.

\section{Declarations}

Conflicts of interest None.

\section{References}

1. Higgins JP, Green S, eds 2011 Cochrane handbook for systematic reviews of interventions: version 5.1.0. Cochrane Collaboration

2. Friedrich JO, Adhikari NKJ, Beyene J (2007) Inclusion of zero total event trials in meta-analyses maintains analytic consistency and incorporates all available data. BMC Med Res Methodol 7(1):5

3. Rosenberg D, Avni T, Tsvetov G, Gafter-Gvili A, Diker-Cohen T (2021) Denosumab is not associatedwith risk of malignancy: systematic review and meta-analysis of randomized controlled trials. Osteoporos Int 32(3):413-424

Publisher's note Springer Nature remains neutral with regard to jurisdictional claims in published maps and institutional affiliations. 